\title{
Support failure of a high-stress soft-rock roadway in deep coal mine and the equalized yielding support technology: a case study
}

\author{
Lihui Sun ${ }^{1,2} \cdot$ Haoyuan $\mathrm{Wu}^{1,2} \cdot$ Bensheng Yang ${ }^{1,2} \cdot$ Qiangqiang $\mathrm{Li}^{1,2}$
}

Received: 8 January 2015/Revised: 16 February 2015 / Accepted: 1 June 2015 / Published online: 30 November 2015

(C) The Author(s) 2015. This article is published with open access at Springerlink.com

\begin{abstract}
There are many soft-rock roadway coal mines in China. The surrounding rocks of the high-stress soft-rock roadways in deep mine are especially difficult to be supported using the traditional supporting way. In this study, the south wing rail roadway on the second level of Yunjialing coal mine in China was used as an example to analyze the deformation and failure characteristics and influencing factors of roadway. On this basis, this study proposed the equalized yielding support idea which employs the yielding rings to realize the pressure equalization on the bolts and cables in the section. To achieve this purpose, the first bolt-mesh-cable equalizing pressure yielding support was integrated with the second grouting reinforcement. The results proved that the yield rings of the bolts and cables on the spandrel of the arched roadway firstly developed yielding deformation; then the deformation extended to the vault of the roadway; the bolts and cables achieved a yielding extreme value of 15 and 18 tonnes, respectively. The roadway surrounding rock tended to be stable at the 26th day after the maintenance. The equalizing pressure yielding supporting technology plays a moderate pressure-releasing and actively controlling role on the surrounding rocks in the soft-rock roadway with large deformation.
\end{abstract}

Keywords Deep-well high-stress · Soft-rock roadway · Equalized yielding support · Grouting reinforcement

\section{Introduction}

Soft rock mines widely distribute in China (Niu et al. 2011) and extend to the depth at a speed of $8 \mathrm{~m} / \mathrm{a}$. The coal and rock masses in the deep mine are characterized by "three highs and one disturbance". The large deformation and failure of surrounding rocks and the floor heave of the roadway etc. seriously affect the safe production of the coal mine (He et al. 2005, 2006; He 2014). Therefore, the supporting problem of such roadway restricts the development of coal mine (Bai et al. 2008). Owning to differences of the geological

Lihui Sun

sunlihui78@163.com

1 College of Resource, Hebei University of Engineering, Handan 056038, China

2 Collaborative Innovation Center of the Comprehensive Development and Utilization of Coal Resource, Handan 056038, China structure, mining depth, and surrounding rock properties, a variety of roadway-controlling technologies have been proposed. However, these technologies fail to be promoted and applied widely. The high-stress soft-rock roadway controlling technology in the deep mine has been the hot research focus. Lots of existing studies have been made to improve the surrounding rock strength, the supporting material strength, and the coupling of surrounding rock with support and got fruitful achievements (Bai et al. 2007; Kang et al. 2010). However, the equalized yielding support technology for the high-stress soft-rock roadway has been rarely reported (Cheng 2004; Shen and Li 2005). In this study, the south wing rail roadway on the second level in Yunjialing coal mine in China was used as an example to analyze the characteristics, deformation rule, and deformation characteristics of the surrounding rocks. On this basis, it proposed the equalized yielding support technology for the roadway with high stress and soft rocks. Field industrial experiment suggested the equalized yielding support technology could avoid the uncontrollable deformation of surrounding rocks 


\begin{tabular}{|c|c|c|}
\hline Columnar & \begin{tabular}{|c} 
Layer \\
thicknessr \\
(m)
\end{tabular} & Description \\
\hline & 0.5 & \#1 coal \\
\hline$(\cdots \cdots \cdots \cdots \cdots$ & 0.35 & Carbonaceous mudstone \\
\hline 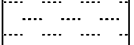 & 7.6 & Siltstone \\
\hline (…....... & 7.5 & Fine sandstone \\
\hline an..... & 0.35 & Carbonaceous mudstone \\
\hline & 3 & \#2 coal \\
\hline & 0.6 & Siltstone \\
\hline & 1 & Fine sandstone \\
\hline
\end{tabular}

Fig. 1 Histogram of the surrounding rocks

and applied uniform stresses on the internal support in the section. The surrounding rock controlling effect of the support technology was significant.

\section{Basic conditions of test roadway}

The second level in Yunjialing coal mine refer to -150 to $-450 \mathrm{~m}$ in depth respectively. The south wing rail roadway is $650-750 \mathrm{~m}$ deep and $850 \mathrm{~m}$ long. The strata in this roadway basically include carbonaceous mudstone, sandmudstone, and fine sandstone with developed joints. Since these strata are vulnerable to bulking deformation, the roadway exhibits a poor overall stability. Figure 1 is a histogram of the surrounding rocks on the two levels.

The roadway in this study was originally supported using bolt-beam-mesh-cable. The bolt used the screw-thread steel bolt spaced by $800 \mathrm{~mm} \times 700 \mathrm{~mm}$ and connected by $\# 14$ steel ladder beam; the specification of top cable was $17.8 \mathrm{~mm} \times 8000 \mathrm{~mm}$, while the side cable was $17.8 \mathrm{~mm} \times$ $4500 \mathrm{~mm}$; the tray of the bolt was $10 \mathrm{~mm} \times 100 \mathrm{~mm} \times$ $100 \mathrm{~mm}$, while that of the cable was $10 \mathrm{~mm} \times 300 \mathrm{~mm} \times$ $300 \mathrm{~mm}$; the steel bar mesh was welded using 8 steel. During the construction, the bolt and cable were applied with a pretension force of 80 and $100 \mathrm{kN}$, respectively. I-steel was used to strengthen the support on local crushing area. The roadway was completed on September 2008 and experienced two maintenances subsequently. However, the roadway is still in large deformation, which is beyond the normal use.

\section{Deformation and failure characteristics of roadway with high stress and soft rocks}

\subsection{Support failure}

The roadway was completed on December 2008. However, most of roadway was repaired for twice 1 year later.
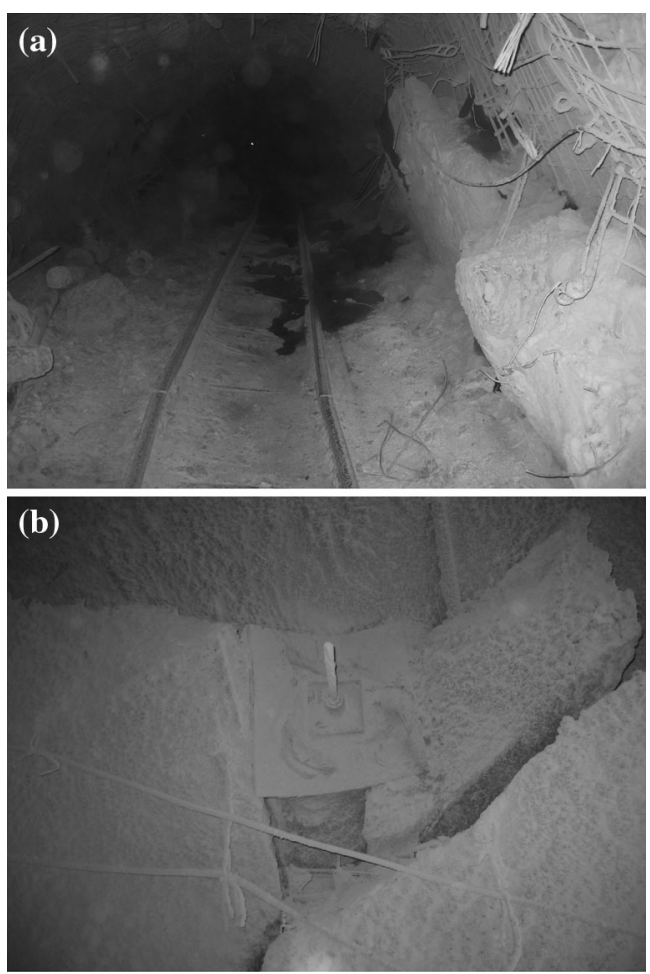

Fig. 2 Failure of roadway surrounding rocks. a Failure of the roadway. b Failure of the wall

Through field observation and geological condition analysis, the deformation and failure law of the roadway was concluded as follows:

(1) The surrounding rocks show fierce deformation, poor stability, and high ground stress. Shortly after the excavation and the two maintenances, the arch angle of the roadway deformed greatly and even the surrounding rocks tend to be instable. Figure 2 illustrates the roadway failure effect.

(2) The surrounding rocks are rheological. The mine pressure observation after the two maintenances suggest that the surrounding rocks from the surface to the depth of $8 \mathrm{~m}$ moved significantly. Moreover, after the roadway maintenances, the roadway movements spent 80 days to turn stable. The roof and floor of the roadway had a deformation of $560 \mathrm{~mm}$ on average, while the two sides converged by $890 \mathrm{~mm}$ on average. The deformation of the two sides exceeded the deformation of roof and floor in this roadway.

\subsection{The causes for roadway deformation}

(1) The complex geological conditions. The south wing rail roadway passes through several strata, including mudstone, san-mudstone, fine sandstone, and coal 
seam. The ground stresses of two holes were measured by using the stress relieving method in the substation of the mining area at two levels. The maximum principal stresses are 19 and $18.52 \mathrm{MPa}$ respectively; while the minimum principal stresses are 9.12 and $8.63 \mathrm{MPa}$; the intermediate principal stresses are 16.25 and $15.67 \mathrm{MPa}$, respectively. Both the maximum and minimum principal stresses are horizontal principal stresses. The maximum principal stresses are at NE85.9 and NE87. ${ }^{\circ}$. The intermediate principal stresses are vertical principal stresses in downward directions. So the roadway is in near southnorth direction, with the maximum horizontal principal stress of $19 \mathrm{MPa}$ in the near east-west direction. The axial direction of the roadway is approximately perpendicular to the maximum horizontal principal stress direction. This situation is unfavorable for the roadway maintenance.

(2) The hydrophilic expansion of the surrounding rocks. The mineral compositions in the rocks, such as kaolinite and montmorillonite, were in high contents. In case of water accumulating in the roadway during roadway repairment, the deformation of corresponding position would be intensified and expanded. These components contain amounts of expansive clay minerals, which have poor water stability and are liable to weathering and deliquescence.

(3) The anchorage structure fails to form the active bearing as soon as possible. The key for the active control of the soft roadway support is to improve the residual strength of loose rocks to give full play to the active bearing capacity of the surrounding rocks. Mine pressure observation shows that the cable can achieve a pretension of $100 \mathrm{kN}$, while the bolt has a pretension force of $30-40 \mathrm{kN}$ generally. Therefore, the shallow anchoring structure formed by bolt and surrounding rocks present insufficient active bearing capacity. Moreover, the cable support is generally lagged behind of heading end by certain distance. The anchoring structure formed by the bolt, cable, the surrounding rocks fail to control intense surrounding rock deformation due to the insufficient overall active bearing capacity at the initial stage of the excavation. Therefore, serious deformation of the surrounding rocks appears and calls for repeated maintenances.

(4) The overall uneven stressing of bolt and cable. The stressing of bolt and cable on the spandrel of the roadway is as high as $85 \%$ of breaking force. While the stresses on the bolt and cable on other positions are merely $50 \%$ of the breaking force.

Figure 3 illustrates the stress distribution of traditional bolt-mesh supporting and equalized yielding support, as
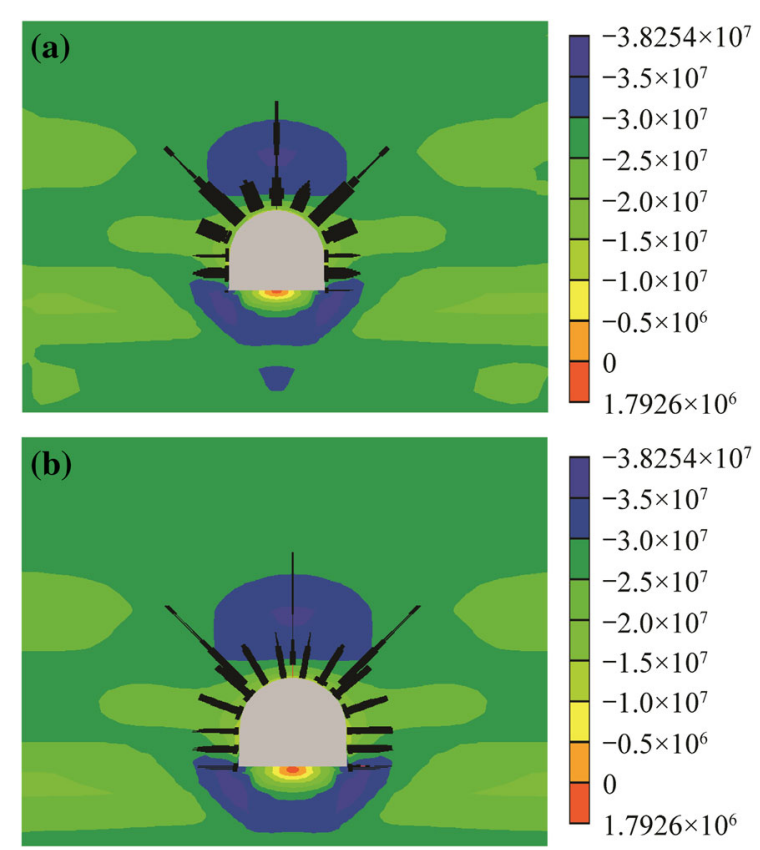

Fig. 3 The contrast of traditional bolt-mesh supporting and equalized yielding support. a Traditional bolt support of roadway. b Qualized yielding support of roadway

well as the stress states of bolts and cables. It can be found that there was little difference in the stress distribution of roadway surrounding rock by using these two supporting schemes, except that the uneven high-stress zone formed in the deep roadway floor. However, there were great difference being found in the stress states of bolts and cables. The stress of the bolts in the whole section of the roadway with traditional bolt-mesh supporting was uneven, where the stress of the vault of roadway was great, and that of the two sides of roadway and floor bolt was small. In terms of the stress state of cables, it reflected that the stress of cables at the shallow section was great, while that of the cables at the deep section was small. On the contrary, the stress of bolts and cables in the roadway with equalized yielding support was relatively even. It suggested that the stress of bolts and cables in the section was more even and reasonable after yielding to reduce the fractures of local bolts and cables.

\section{Equalized yielding pressure support technology for roadway with high stress and soft rocks}

\subsection{Equalized yielding support theory}

The support of the soft-rock roadway in the deep mine are likely to be stressed unevenly. The bolt-mesh-cable coupling can eliminate the nonuniform stressing condition of 


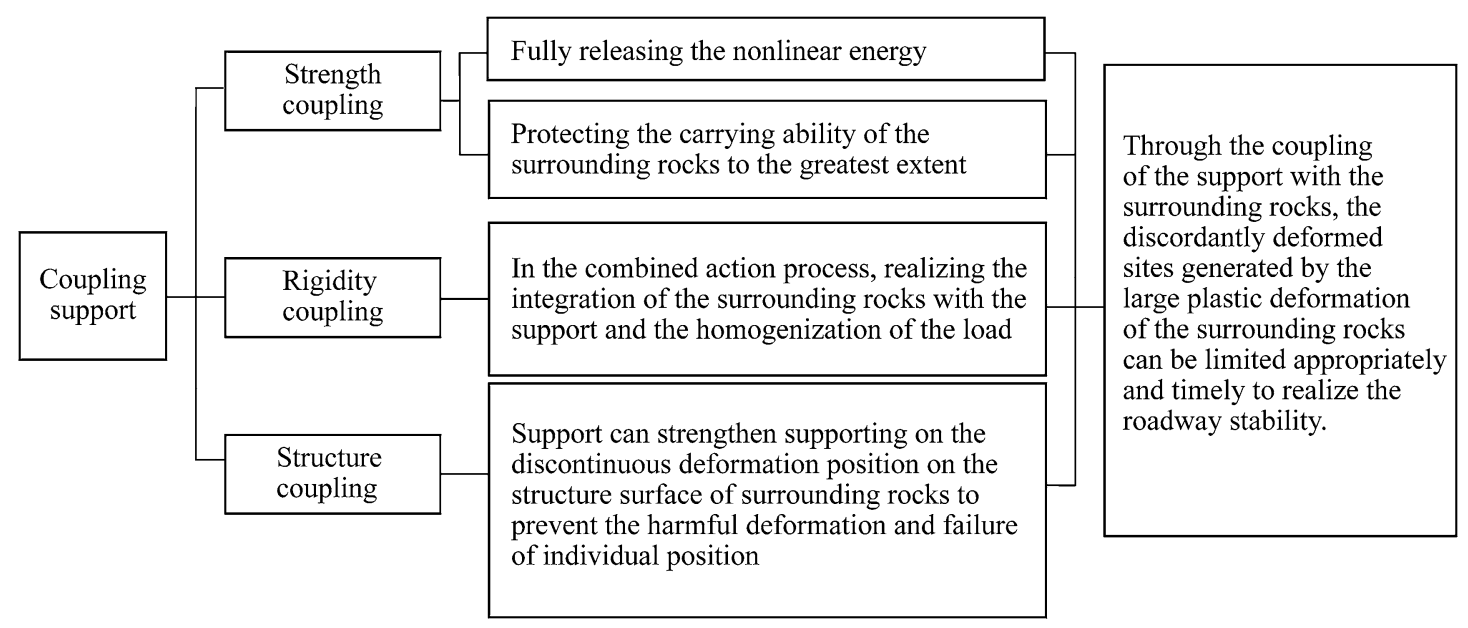

Fig. 4 Coupling support theory

the support structure through the coupling of the bolt mesh and surrounding rocks. The coupling way coordinates the deformation of the surrounding rocks and realizes the integration of the supporting and the uniform distribution of the load. Finally, the stability of the surrounding rocks can be achieved. The support of the soft-rock roadway in the deep mine is basically characterized the coupling of the strength and rigidity of the surrounding rocks with the support, as shown in Fig. 4 (Ren 2010; Lu et al. 2011).

The mechanism of equalized yielding support is as follows: due to the redistribution of stress, the stress concentrated at part of roadway after the excavation and support of roadway. Meanwhile, the surrounding rocks deformed sharply so that the stress of the bolts and cables at this part increased. Once the stress reached the yielding limit of bolts and cables, they yielded through the deformation of yield rings. At the same time, the high stress of surrounding rock gradually transferred to the neighboring bolts and cables. When the bolts and cables reached the yielding limit, they yielded immediately so that the high stress of surrounding rock passed on to the bolts and cables around. The process cycled in this way until the deformation of roadway surrounding rock stabilized. Thereby, the stress of bolts and cables was even, as seen in Fig. 5.

\subsection{Equalized yielding support plan}

Basing on the characteristics and causes of the deformation and failure of the roadway, the support technology in this study aims to control the local violent deformation, improve the overall bearing ability of the support structure, and realize the equalized stress on the support. The bolt with high strength and cable bearing high pretension force were used to bear the pressure on the anchoring structure. Moreover, yielding ring was employed to realize the uniform stress on the support components. The secondary grouting in the surrounding rocks can further improve the self-bearing ability of the surrounding rocks and thus to keep the stability of the roadway constantly. Figures 6 and 7 show the section of the supporting way, and the yielding ring respectively.

(1) First support.

The bolt with ultra-high strength of $20 \mathrm{~mm} \times 2800 \mathrm{~mm}$, lengthening anchorage length of $1400 \mathrm{~mm}$, pretension force of $80 \mathrm{kN}$, and tensile strength of $250 \mathrm{kN}$ was used. The protective metal mesh was in specification of $6.5 \mathrm{~mm} \times$ $100 \mathrm{~mm} \times 80 \mathrm{~mm}$. The bolts were connected using the reinforced bar ladder beam of $14 \mathrm{~mm}$. The tray was a square high-strength plate in size of $200 \mathrm{~mm} \times 200 \mathrm{~mm} \times 10 \mathrm{~mm}$ and strength of $280 \mathrm{kN}$ above. The bolts were spaced by $800 \mathrm{~mm} \times 800 \mathrm{~mm}$.

The roof is supported by the nest bolt of $18.9 \mathrm{~mm} \times$ $8000 \mathrm{~mm}$; the two sides were supported using nest cables of $18.9 \mathrm{~mm} \times 4500 \mathrm{~mm}$, with anchorage of $2.2 \mathrm{~m}$ long and pretension force of $100 \mathrm{kN}$; the tray for the anchor rope was the spheroidal stray of $300 \mathrm{~mm} \times 300 \mathrm{~mm} \times$ $12 \mathrm{~mm}$ with high-strength. The cables were spaced by $1810 \mathrm{~mm} \times 1600 \mathrm{~mm}$.

The pressure yielding pipe was prepared by the thread steel with high strength. The anchor yielding ring is $20 \mathrm{~mm}$ long; the pressure yielding pipe of the anchor cable is $30 \mathrm{~mm}$ in length. And the yielding values of the anchor bolt and the anchor cable are designed to be 15 and 18 tonnes, respectively. If yielding ring is used in coal roadway, the length of the yielding ring needs to be properly increased according to the measured value of surrounding rock deformation in the field roadway so as to adapt to the deformation.

(2) Second reinforcing-grouting in the surrounding rocks. 

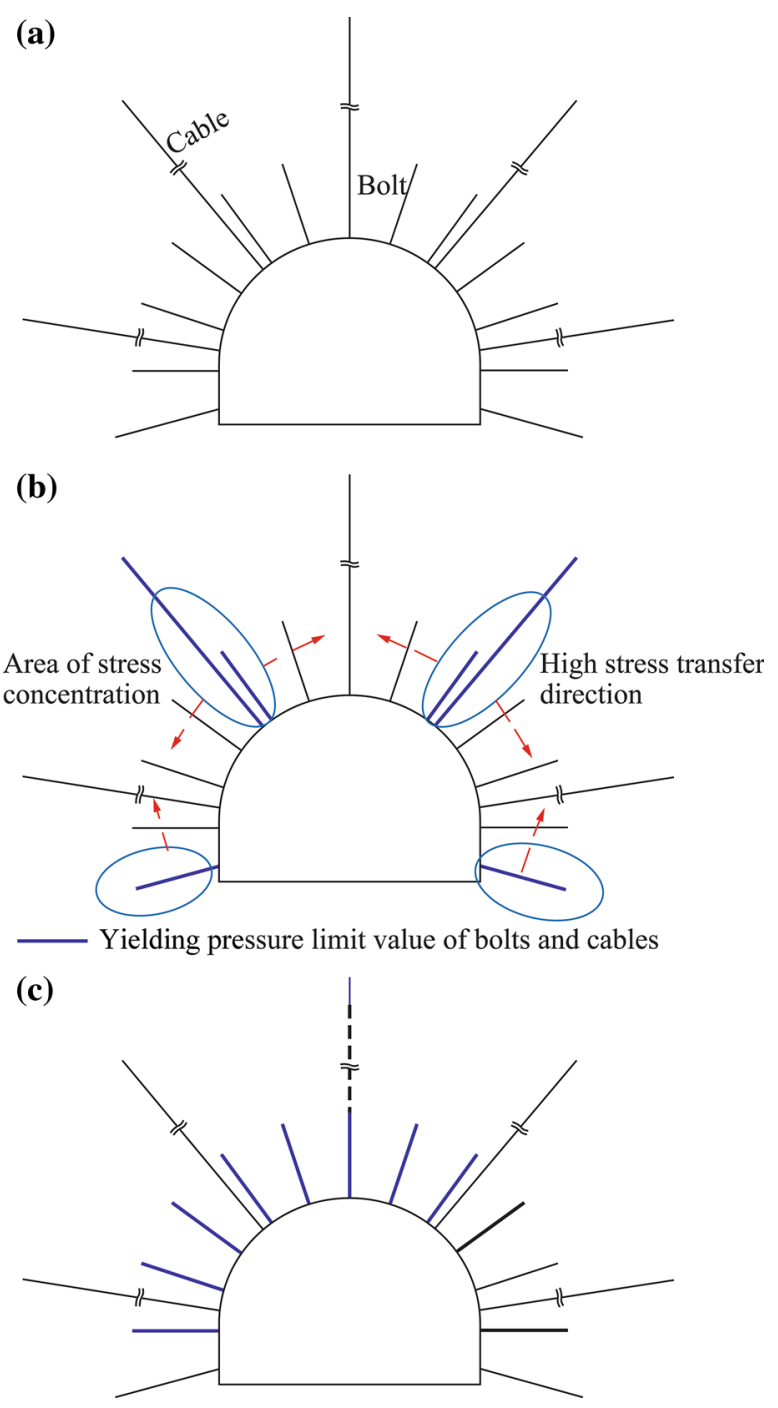

Fig. 5 Evolution model of qualized yielding support of roadway. a Initial stage of bolt support of roadway. b Yielding pressure stage of local roadway. c Equalized pressure of bolts and cables of whole roadway

The grouting anchor rode was $2000 \mathrm{~mm}$ long. The bolt for base angle grouting was $3000 \mathrm{~mm}$ long and spaced by $1350 \mathrm{~mm} \times 1600 \mathrm{~mm}$. The grouting in the surrounding rocks was implemented after the first support. \#525 portland cement and ACZ-I cement grout additive were utilized as grouting material. The amount of additive is $8 \%$ of that of cement; water cement ratio is $2: 1$; the grouting pressure is controlled at 3-5 MPa. The grouting amount is determined by considering three perspectives: the grouting requires to be ceased in the cases when grouting pressure reaches $3-5 \mathrm{MPa}$, or the cement more than two bags is grouted. The grouting also has to be stopped when cement leakage occurs in the rear grouting pipe or the zone around the grouting hole in the grouting process.
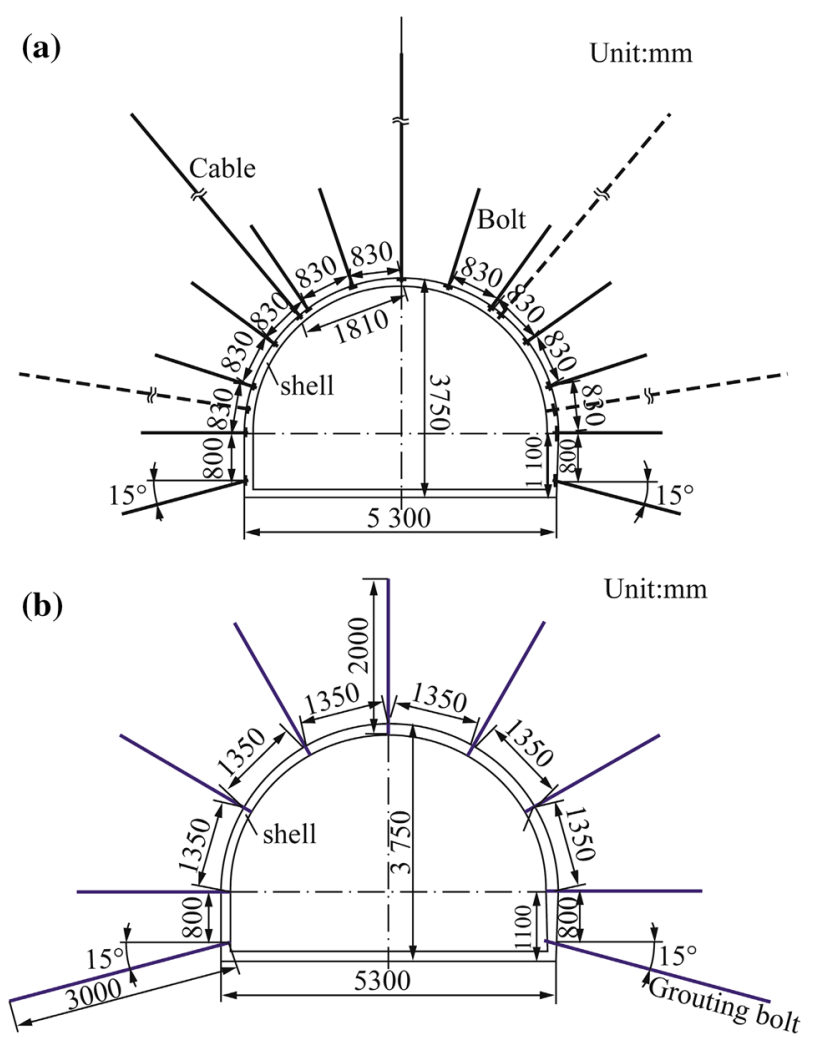

Fig. 6 Support parameter of roadway. a The first support. b The second reinforcing-grouting
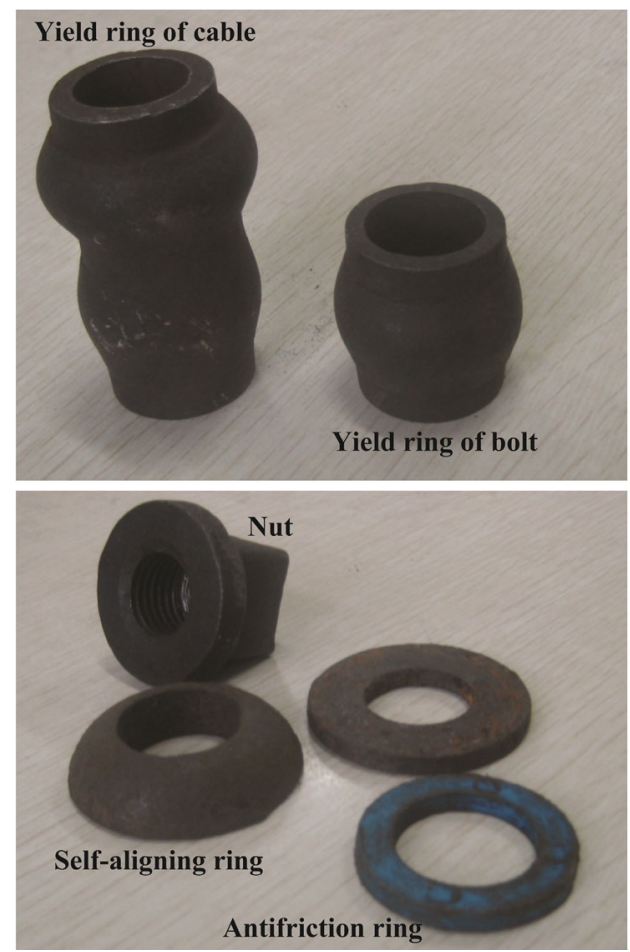

Fig. 7 Yelding ring and auxiliary components of bolts and cables 


\subsection{Numerical simulation on the equalized yielding support}

According to the geological conditions of the south rail roadway on second level, a numerical model of $50 \mathrm{~m} \times 50 \mathrm{~m} \times 50 \mathrm{~m} \quad$ (length $\times$ width $\times$ height $)$ was established using FLAC3D numerical simulation software. The sides and bottom of the model were set with limited displacement boundary. The upper surface of the model was free boundary and was applied with the vertical load of $19 \mathrm{MPa}$. The bolts and cables were simulated using cable unit. Section 4.2 shows the support parameters. The simulation steps include excavation, support, and grouting. Given the role that grouting played in improving the strength of surrounding rock, so simulation grouting was realized by improving the cohesion force and friction angle of surrounding rock.

As seen in Fig. 8, in the case of using equalized yielding support plan, the roof and floor are shown a cumulative deformation of $6 \mathrm{~cm}$, while the two sides show a cumulative deformation of $10 \mathrm{~cm}$. The large deformation of the roof and bottom are mainly observed in vault and the shallow surrounding rocks within $1.5 \mathrm{~m}$ of the roadway. By reinforcing, roadway floor show smaller deformation and deformation influencing area. The large deformation on the two sides of the roadway is concentrated on the stringcourse of the roadway. Moreover, the influences of horizontal deformation in the surrounding rocks are larger than that of the roof and floor.

As shown in Fig. 9, the horizontal stress concentration of the surrounding rocks in the roadway mainly distributes

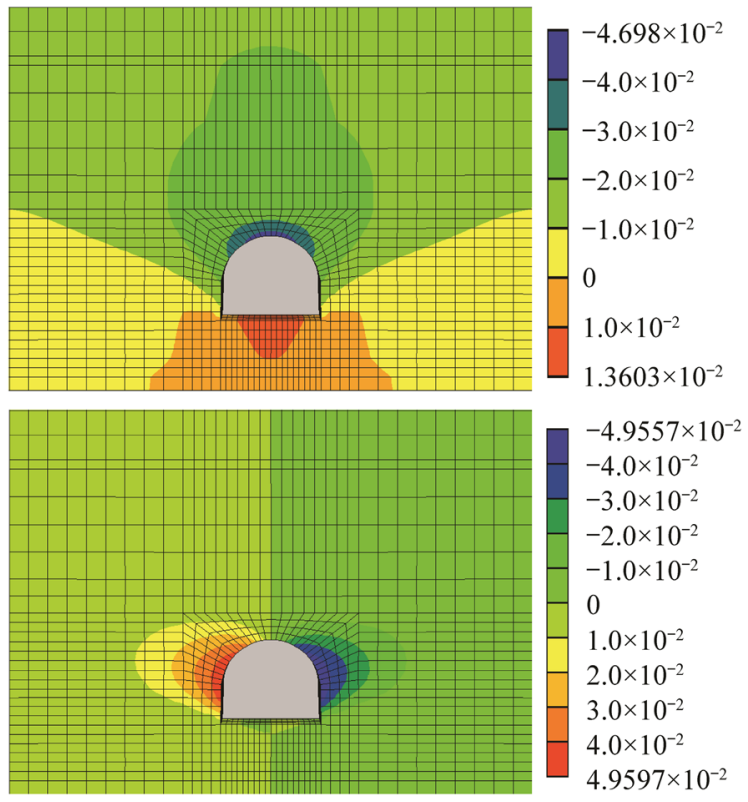

Fig. 8 Deformation of qualized yielding support of roadway

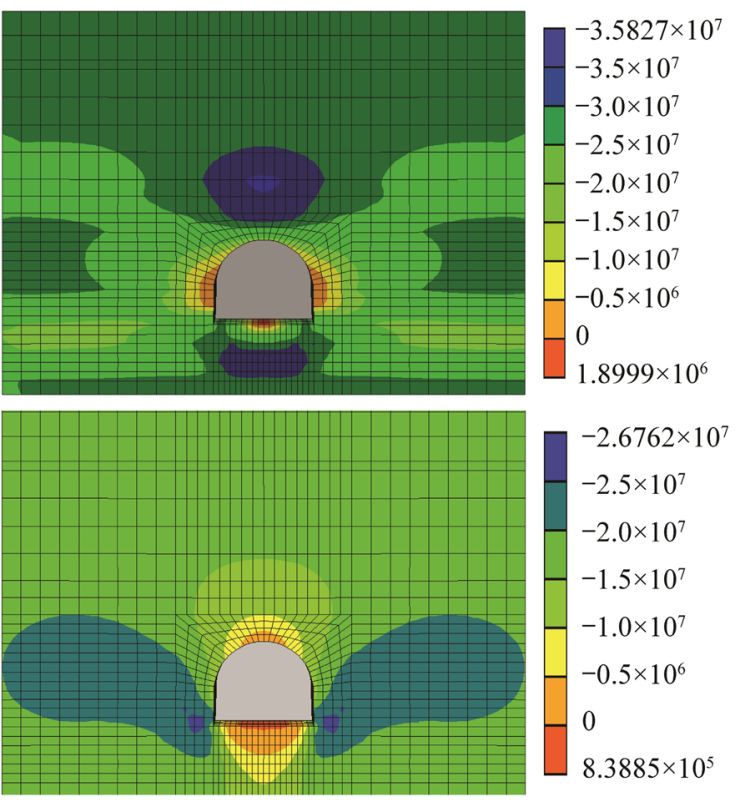

Fig. 9 Stress distribution of qualized yielding support of roadway

in the deep surrounding rocks of the roof and floor of the roadway. The maximum horizontal stress is $4 \mathrm{~m}$ away from the roof. The stress in the roadway maximizes at 35.82 MPa, with a stress concentration coefficient of 1.36. The vertical stress concentration area of the surrounding rocks of the roadway is mainly in the slope angel on the middle-to-low part of the two sides, with a maximum stress of $26.76 \mathrm{MPa}$ and the stress concentration coefficient of 1.53. Especially, the concentration of the vertical stress on the two slope angles of the roadway requires to be given priority in the making controlling measures. In case of the deformation and failure, grouting needs to be applied in time. In addition, the bolt and cable are under the stress of 136 and $204 \mathrm{kN}$, respectively, which are both in the stressing ranges of them. The grouting reinforces the strength of the surrounding rocks in the roadway. The shallow surrounding rocks are in high strength and are conductive to maintain the stability of the roadway. Therefore, the equalized yielding support plan proposed is proved to be effective.

Figure 10 shows the deformation of roadway by traditional bolt-mesh supporting. It is obvious that the roadway surrounding rock deformed greatly owing to the unreasonable support parameters and without reinforcing the surrounding rocks by grouting. The subsidence of the roadway roof was up to $60.67 \mathrm{~cm}$ and the floor heave was $18.12 \mathrm{~cm}$. In addition, the maximum deformation occurred at the waist line of the two sides of roadway with accumulative deformation of $83.68 \mathrm{~cm}$. It can be known that the deformation of the roadway with traditional bolt-mesh supporting was greater than that of the roadway by equalized yielding support. 


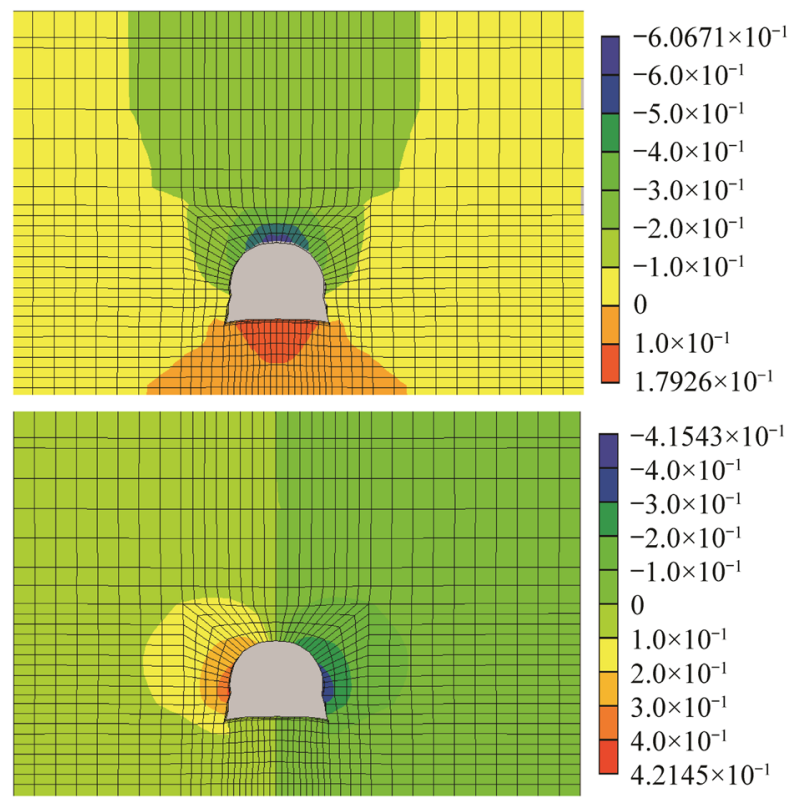

Fig. 10 Deformation of traditional bolt support of roadway

\section{Field industrial test and analysis on test results}

The exampled roadway was repaired by using equalized yielding support plan. The test roadway was $200 \mathrm{~m}$ long. In field, the roadway section was firstly repaired so as to meet the requirements of the designed section. Then, the first support was applied. Five days later, the secondary grouting reinforcement was conducted.

\subsection{Displacement on the roadway surface}

The displacement of the surrounding rocks after maintenance is shown in Fig. 11. It can be seen that the deformation of the surrounding rocks attenuates rapidly and tends to be stable 26 days later. After the roadway deformation tends to be stable, the two sides, and roof and floor move close by 161 and $42 \mathrm{~mm}$ respectively. This technology controls the deformation of the surrounding rocks in the deep roadway with high stress and soft rocks and ensures the stability of the surrounding rocks in the roadway.

\subsection{Stressing analysis on the anchor rod and anchor rope}

Figure 12 shows the stress variations of the bolt and cable. Before the secondary grouting reinforcement, the stresses on the bolt and cable increase rapidly. The stresses on the supports in the section are sequenced in a decreasing order: spandrel $>$ vault $>$ two sides. The yielding ring fails to shift the pressure. After grouting, the stress on the support

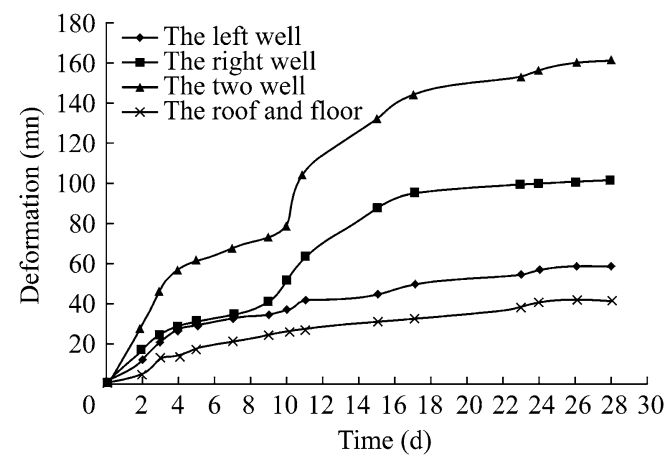

Fig. 11 Deformation of roadway

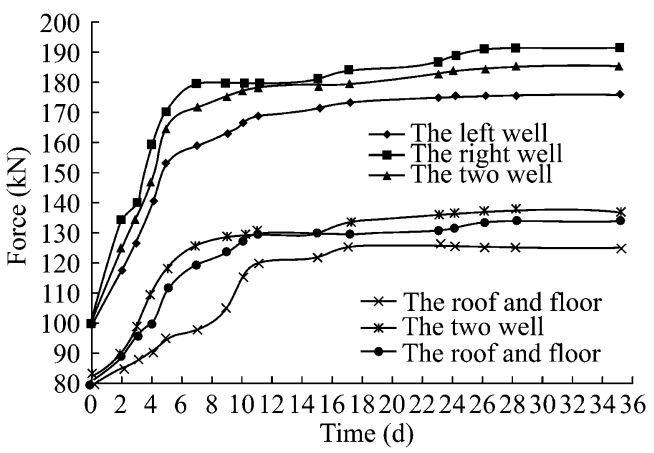

Fig. 12 Force of bolts and cables

grows slowly. Three days later after the grouting, the cable on the spandrel shifts the stress to the vault. The bolt on the vault functions on the 6th day after the grouting. The cable on the spandrel begins to convert the stress on the 5th day after the grouting to the vault. The cable on the vault functions on the 6th day after the grouting. Thirty days after the roadway maintenance, the stress on the support basically is constant. The stress on the cable lies in $176-191 \mathrm{kN}$, while that on the bolt is in $125-137 \mathrm{kN}$. The stresses on the bolt and cable on the both sides are both lower than yielding values.

\section{Conclusions}

(1) The serious deformation of the south wing rail roadway mainly results from the high stress environment, the perpendicular roadway axis direction of the roadway to the maximum horizontal principal stress, the high-content swelling mineral(such as kaolinite) in the rocks, and the poor self-stabilization ability of the surrounding rocks etc.

(2) According to the pressure law of the roadway, this study integrated the equalized yielding support with the grouting reinforcement and used a bolt-meshcable + anchor grouting support technology. 
(3) The roof and both sides of the roadway deformed by $42 \mathrm{~mm}$ and $161 \mathrm{~mm}$ respectively; in the section, the bolt and cable were uniformly stressed in the normal working state. The deformation of the surrounding rocks in the roadway could be controlled effectively.

Acknowledgments Supported by the National Natural Science Foundation of China (51174070).

Open Access This article is distributed under the terms of the Creative Commons Attribution 4.0 International License (http://creati vecommons.org/licenses/by/4.0/), which permits unrestricted use, distribution, and reproduction in any medium, provided you give appropriate credit to the original author(s) and the source, provide a link to the Creative Commons license, and indicate if changes were made.

\section{References}

Bai JB, Wang XY, Yao Z (2007) Study of coupling support in soft rock roadway under high stress. J China Univ Min Technol 36(4):421-425

Bai JB, Wang XY, Jia MK, Hou CJ (2008) Theory and application of supporting in deep soft roadways.Chinese. J Geotech Eng 30(5):632-634
Cheng JY (2004) Application on supporting technology of release equilibrium pressure in high stressing and deformation roadway. Coal Eng 5:79-80

He MC (2014) Progress and challenges of soft rock engineering in depth. J China Coal Soc 39(8):1409-1417

He MC, Xie HP, Peng SP, Jiang YD (2005) Study on rock mechanics in deep mining engineering. Chin $J$ Rock Mech Eng 24(16):2803-2814

He YN, Han LJ, Shao P, Jiang BS (2006) Some problems of rock mechanics for roadways stability in depth. Chin J Rock Mech Eng 25(3):288-295

Kang HP, Wu YZ, Li JB (2010) Analysis on mechanical performances and supporting function of combination components for rock bolting. J China Coal Soc 35(7):1057-1065

Lu YL, Wang LG, Zhang B (2011) An experimental study of a yielding support for roadways constructed in deep broken soft rock under high stress. Min Sci Technol (China) 11:839-844

Niu SJ, Jing HW, Zhang ZY, Yang SQ (2011) Study on control technology of surrounding rocks in deep soft roadway and its application. J China Coal Soc 36(6):914-919

Ren XL (2010) Application on supporting technology of release equilibrium pressure in Yun Jia-ling coal mine. In:The youth technology innovation proceedings of the fifth session of the national coal industry production line, pp 77-81

Shen RS, Li DS (2005) The study of tunnel yield and shotcrete technology. China Min Mag 14(9):63-65 